\title{
THE EFFECT OF BANGGAI YAM (DIOSCOREA ALATA L.) MODIFICATION ON FILM CHARACTERISTICS AS A FILM COATING MATERIAL FOR MODIFIED RELEASE DOSAGE FORMS
}

\author{
YUSRIADI, EVI SULASTRI*, ATHIYAH, NUUR AANISAH
}

Department of Pharmacy, Faculty of Mathematics and Natural Sciences, Tadulako University, Indonesia Email: evisulas3@gmail.com

Received: 08 Mar 2021, Revised and Accepted: 24 Apr 2021

\begin{abstract}
Objective: This study aims to determine the effect of modification of Banggai yam (Dioscorea alata L.) as a coating agent in modified release drug based on the film characteristics.

Methods: Banggai yam starch was physically modified to produce pregelatinized Banggai yam starch (PGBYS) powder as well as chemically to produce pregelatinized Banggai yam starch phthalate (PGBYSP). Powder obtained was each physically and chemically characterized including organoleptics, morphology, tapped density, water content content and degree of substitution. Furthermore, the formulation was made to produce film-coated drug with the same coating agent concentration in 2 formulas: F1 (PGBYSP 6 \%) and F2 (PGBYS 6 \%).

Results: The results were then evaluated including organoleptics, film thickness, morphology, mechanical strength, and film solubility. Results of evaluation showed that film thickness values for both formulas, F1 and F2 respectively, were $0.13 \pm 0.020 \mathrm{~mm}$ and $0.18 \pm 0.005 \mathrm{~mm}$. Mechanical strength included tensile strength consecutively at values of F1=0.08 $\pm 0.005 \mathrm{MPa}$ and F2 $=0.27 \pm 0.05 \mathrm{MPa} \% \%$ elongation of $\mathrm{F} 1=114.16 \pm 11.8 \%$ and $\mathrm{F} 2=164.06 \pm 57.94 \%$; Young's modulus of F1 $=7.3 \times 10^{4} \pm 9.8 \times 10^{-5} \mathrm{MPa}$ and F2 $=1.8 \times 10^{3} \pm 7.9 \times 10^{-4} \mathrm{MPa}$. The solubility of the film-coating in $\mathrm{HCl}$ pH 1.2 medium for $\mathrm{F} 1$ was $7.9 \pm 1.92 \%$ and $\mathrm{F} 2$ was $25.8 \pm 2.42 \%$. In pH 6.8 medium, F1 was $8.6 \pm 2.27 \%$ and $\mathrm{F} 2$ was $11.6 \pm 1.44 \%$, while in pH 7.4 medium, F1 was $19.1 \pm 5.46 \%$ and F2 was $13.1 \pm 1.78 \%$. Both film-coated formulas were soluble in alkaline medium, but F2 could not maintain its conditions in acid medium. This proves that the chemical modification product by esterification to form a film can withstand acidic medium.
\end{abstract}

Conclusion: Therefore, PGBYSP has potential to be used as a coating agent in controlled release drug.

Keywords: Dioscorea alata L., Starch phthalate, Coating material, Modified release

(C) 2021 The Authors. Published by Innovare Academic Sciences Pvt Ltd. This is an open access article under the CC BY license (https://creativecommons.org/licenses/by/4.0/) DOI: https://dx.doi.org/10.22159/ijap.2021v13i4.41343. Journal homepage: https://innovareacademics.in/journals/index.php/ijap

\section{INTRODUCTION}

Film-coated tablets with sufficient thickness provide a targeted and delayed drug release along the intestines. In this case, the drug is usually at the core and released through the coating's dissolution. The targeted drug release requires a protective material that does not break down in the stomach when directed to the small intestine. However, for the colon area, neutral materials resistant to stomach acid and pancreatic enzymes are used. Tablets coating based on gastrointestinal fluid $\mathrm{pH}$, which delays or extends drug release in the stomach's highly acidic condition is preferably designed to dissolve at $\mathrm{pH} 4.8$ and beyond in the intestines [1, 2]. By using polymers that are soluble at $\mathrm{pH} 7$, the tablet coating dissolves and releases the drug content while moving into the colon. A typical coating film material contains polymer, plasticizer, colorant, and solvent as well as need to have certain desired properties such as viscous coating solution, mechanical stability and resistance to body $\mathrm{pH}$. The application of polymer-based formulation to the tablet's surface affects the aforementioned properties $[3,4]$.

Natural polymers are widely explored due to their biodegradable properties and abundant source. Starch is a natural ingredient easily obtained and also beneficial as a coating material because of the biodegradable and thermoplastic behaviour with low-cost production [5]. It is referred to as a hydrophilic matrix, which swells and pruduces a gel that controls the drug release rate. One of the starch sources is water yam, which has high amylose content (21.69-31.56\%) [6]. The amount of amylose determines starches film-forming capacity. However, natural starch lacks some properties such as swelling capacity and satisfactory mechanical properties for tablet coating in certain $\mathrm{pH}$ conditions. Mechanical strength is required to prevent tablets breakdown in the stomach fluid and subsequent coat processing. Therefore, physical, chemical or combined modification of starch is needed to improve its mechanical properties and ability to release the drug content at certain $\mathrm{pH}[7,8]$.

Dimantov et al. reported that corn coating material of high amylose content has potential for colonic release. Furthermore, increasing its concentration leads to decreased solubility in the stomach and small intestine and resistance to pancreatic enzymes [9]. Meanwhile, Surini et al. stated cassava starch phthalate is more soluble in alkaline than the acidic solution when used as an enteric coating material [10]

Water yams (Dioscorea alata L.) preparation as a starch source was carried out according to the description above. They were harvested from the Banggai Islands of Central Sulawesi, Indonesia. Furthermore, physical and chemical treatments were performed to determine the modification effect as a coating material for targeted drug release based on the film characteristics.

\section{MATERIALS AND METHODS}

\section{Materials}

Banggai yams (Dioscorea alata. L) were harvested from Banggai Islands of Central Sulawesi, Indonesia and processed in our laboratory. The materials used in this study were hydrochloric acid, phthalic anhydride, sodium sulfate anhydridate, potassium hydrogen phthalate, anhydrous sodium sulfate, and phosphate buffer ( $\mathrm{pH} 6.8$ and $\mathrm{pH}$ 7.4) that purchased from Merck and Co., Inc, Germany. While ethanol, glycerol, distilled water and sodium hydroxide were purchased from Brataco, Indonesia.

\section{Extraction of Banggai yam starch}

The skin of fresh Banggai yams are removed and washed thoroughly using running water. The clean tubers are cut into slices. The slices soaked in salt water and filtered repeatedly until the filtered water is clear. The filter is left for $2 \times 24 \mathrm{~h}$ until the water yam starch settles. The precipitate in the form of water yam starch is dried in the oven for $19 \mathrm{~h}$ at a temperature of $60{ }^{\circ} \mathrm{C}$. The dry starch was ground gently with a mortar, then sifted with 80-mesh sieve [11].

Preparation of pregelatinized Banggai yam starch (PGBYS)

$30 \mathrm{~g}$ of water yam starches were dispersed in $60 \mathrm{ml}$ of distilled water then heated at $70{ }^{\circ} \mathrm{C}$ while stirring at $200 \mathrm{rpm}$ for $10 \mathrm{~min}$. 
Then, oven-dried at $60^{\circ} \mathrm{C}$ for $24 \mathrm{~h}$. The dry pregelatinized water yam starch were sieved with 80-mesh sieve [12].

Esterification of pregelatinized Banggai yam starch phthalate (PGBYSP)

$10 \% \mathrm{w} / \mathrm{v}$ of pregelatinized banggai yam starch in distilled water was reacted with $16.67 \% \mathrm{v} / \mathrm{v}$ phthalic anhydride solution in ethanol on the digital stirrer at $100 \mathrm{rpm}$. When the reaction occurred, $\mathrm{NaOH}$ solution $10 \mathrm{~N}$ was dropped continuously to adjust the $\mathrm{pH}$ level to 8-9 and $10 \mathrm{mg}$ anhydrous sodium sulfate was added every $6 \mathrm{~min}$ until the reaction was complete. After that, the stirring is continued for up to $60 \mathrm{~min}$. Then, solution was left for $24 \mathrm{~h}$.

Furthermore, it is neutralized by adding $\mathrm{HCl}$. It was left until a sediment is formed. The precipitate was washed by using $20 \mathrm{ml}$ of $50 \%$ ethanol for 20 times and evaporated at temperature $60^{\circ} \mathrm{C}$. The pregelatinized phthalate water yam starch formed was sieved with an 80-mesh sieve [13].

\section{Characterization of PGBYSP powder}

\section{Organoleptic and morphological properties}

Morphologies of the powder obtained were observed using a scanning electron microscope (FEI S50 ${ }^{\circledR}$ ).

\section{Tapped density}

The tapped densities were determined according to USP methods under modification. A total of $10 \mathrm{~g}$ of starch was placed into a $50 \mathrm{ml}$ measuring cylinder and the initial volume was recorded. The cylinder was tapped for 500 times until the starch volume reached the minimum and the final volume was noted [14].

\section{Water content}

The amount of the water content, based on SNI 08-7070-2005 was obtained by weighing $2 \mathrm{~g}$ of starch, then heating it to a constant weight $\left(105^{\circ} \mathrm{C}\right)$. Value of the water content was noted [15].

\section{Degree of substitution}

$50 \mathrm{mg}$ of PGBYSP was dissolved in $25 \mathrm{ml}$ of $\mathrm{NaOH} 1 \mathrm{~N}$ solution. Then the absorbance was measured at the wavelength of $271.8 \mathrm{~nm}$ using UV-Vis spectrophotometer $\left(\mathrm{CECIL}^{\circledR}\right)$. The degree of phthalic substitution was calculated using the equation [10]:

$$
\text { Degree of substitution (DS) }=\frac{162 \times \% \text { phtalate }}{14.900-(148 \times \% \text { phtalate })}
$$

\section{Preparation of the films}

The formulation of PGBYS and PGBYSP as film-forming polymer can be seen in table 1 below:

\section{Table 1: Formulation of film coated}

\begin{tabular}{lll}
\hline Ingredients & Formulation & \\
\cline { 2 - 3 } & F1 & F2 \\
\hline PGBYS (\%) & - & 6 \\
PGBYSP (\%) & 6 & - \\
Glycerol (\%) & 3 & 3 \\
Distilled water (\%) & 50 & 50 \\
\hline
\end{tabular}

Each formula was heated under stirring until a thick solution formed. Then left for $1 \mathrm{~h}$ to remove air bubbles. The viscosity of the film solution was measured using the Brookfield Viscometer. The film solution was transferred into a petri dish and placed in oven at $55{ }^{\circ} \mathrm{C}$ to form a flexible film layer. Finally, the films were cut into pieces of $3 \times 3 \mathrm{~cm}^{2}$.

\section{Characterizations of film coated polymer}

\section{Organoleptic and morphological evaluation}

For organoleptic and morphological evaluation and SEM analysis were performed.

\section{Film thickness}

The film thickness was performed by using digital caliper.

\section{Mechanical strength}

3 pieces of film were prepared for each formula measuring 10x30 $\mathrm{mm}$ and clamped to the machine. Then, the films were pulled apart at a speed of $50 \mathrm{~mm} / \mathrm{min}$ and the value of the force to tear the film was considered to be the maximum stress $\left(\mathrm{F}_{\max }\right)$. The resulting tensile strength, $\%$ elasticity (\% elongation), and Young's modulus are calculated.

\section{Film solubility}

The test was carried out by incubating the film at $50 \mathrm{ml}$ of $\mathrm{HCl} \mathrm{pH}$ $1.2 \pm 0.05$ for $2 \mathrm{~h}$ at $37 \pm 0.5^{\circ} \mathrm{C}$. The $\mathrm{HCl}$ solution is removed and the film was placed in a desiccator until constant weight obtained. After $2 \mathrm{~h}$ of incubation, the $\mathrm{HCl}$ solution was replaced with $50 \mathrm{ml}$ of phosphate buffer solution $\mathrm{pH} 6.8 \pm 0.05$ which was incubated again for $3 \mathrm{~h}$ at $37 \pm 0.5{ }^{\circ} \mathrm{C}$. The same procedure was performed by using phosphate buffer $\mathrm{pH} 7.4 \pm 0.05$. The dissolution of film coating in intestinal fluids is expressed in percent of the weight of film lost [16].

\section{Statistical analysis}

All experiments were performed in triplicate and the data was analysed using IBM SPSS Statistics 26.0. Effects of the modification of Banggai yam starch on the characteristics of films were subjected to one-way ANOVA to determine the level of significance. Statistical significance was set at $\mathrm{p}$-value $<0.05$.

\section{RESULTS AND DISCUSSION}

The extraction yield obtained from Banggai yam starch, pregelatinized Banggai yam starch (PGBYS) and esterification of pregelatinized Banggai yam starch phtalate (PGBYSP) were $10 \%$, $76.6 \%$, and $77.0 \%$, respectively.

\section{Characterization of pregelatinized phthalate Banggai yam starch powder (PGBYSP)}

The results of the powder characterization were described in table 2

\section{Organoleptic and morphological properties}

Scanning electron microscope micrograph shows that the Banggai yam starch granules have oval and elliptical shapes. In PGBYS and PGBYSP granules, there is an aggregation of starch granules, which indicates that the starch has undergone a pregelatinized process. In addition, this fig. proves that the esterification process does not affect starch morphology [17].

\section{Tapped density}

The result shows that PGBYSP is more compressed than PGBYS. This is because the esterification process is stirred at $1000 \mathrm{rpm}$ for 120 min resulting in a smaller powder size so that the PGBYSP is more compressed.

Table 2: Results of the powder characterization

\begin{tabular}{lll}
\hline Parameter & mean \pm SD (n=3) & \\
\cline { 2 - 3 } & PGBYS & PGBYSP \\
\hline Organoleptic & Yellowish white powder and distinctive odor & Brownish white powder and odorless \\
Tapped density $(\mathrm{g} / \mathrm{ml})$ & $0.67 \pm 0.02^{*}$ & $1.07 \pm 0.06^{*}$ \\
Water content $(\%)$ & $9.82 \pm 0.54^{*}$ & $8.24 \pm 0.78^{*}$ \\
Substitution degree & - & $0.07 \pm 0.01$ \\
\hline
\end{tabular}

Data represents mean $\pm S D(n=3),{ }^{*}$ Statistically significant difference at ${ }^{*} \mathrm{p}<0.05$ 


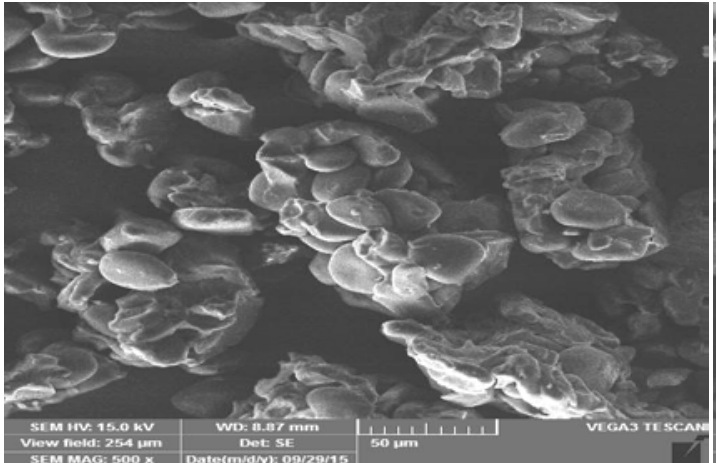

(a)

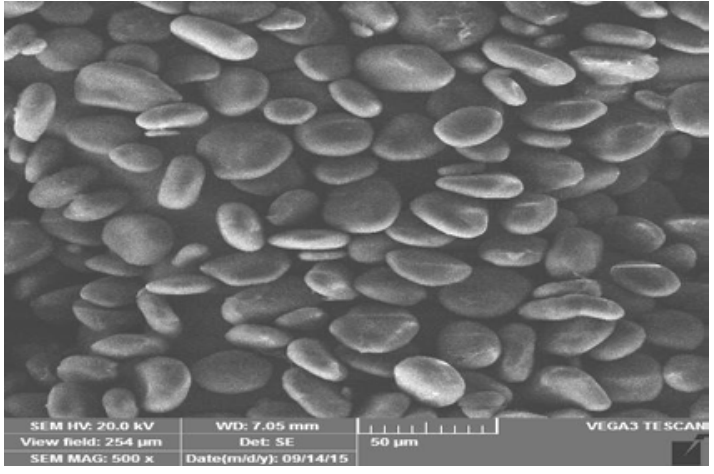

(b)

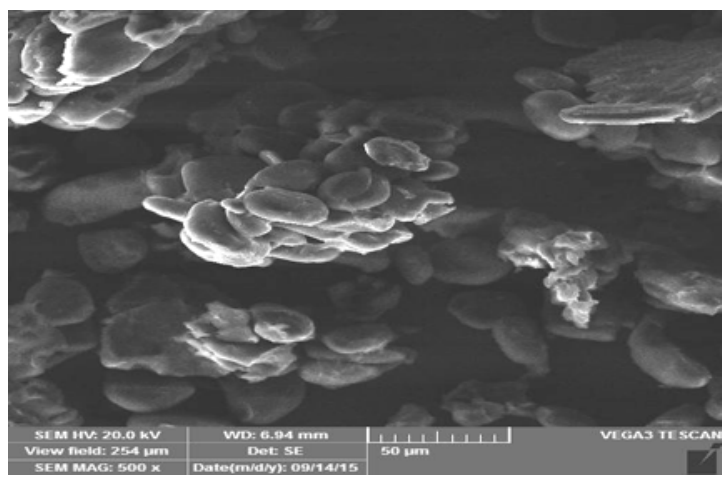

(c)

Fig. 1: Scanning electron microscope micrograph of the produced Banggai yam starch powder with 500× magnificancy (a) Unmodified Banggai yam starch (b) PGBYS (c) PGBYSP

\section{Water content}

Table 2 shows that PGBYS has a higher water content than PGBYSP. However, these results are not much different and still within the range of water content of Dioscorea alata starch of 6-11\%. Lower water content increases the stability and shelf life of yam starch as it prevents the growth of microorganisms [18].

\section{Degree of substitution}

The DS value for PGBYSP was 0.07, meaning 7 phthalate groups were substituted for every 100 units of PGBYS anhydrous glucose. This esterification which took place in an aqueous medium reduces acid anhydride to a less reactive carboxylic acid, yielding a small DS value which is often 0.2 [19]. The medium was preferred because of being safer than organic media. Irrespective of the DS value, its effect is quite significant. The distinguishing characteristic was that the PGBYSP film solution's viscosity was lower than that of an ordinary PGBYS.

\section{Formulation of the coating film polymer}

Coating films formulation requires plasticizers that increase flexibility and minimize brittleness [20]. About $50 \% \mathrm{v} / \mathrm{v}$ glycerol was used because, during the preliminary observation with the same concentration, other types of plasticizers such as propylene glycol and polyethylene glycol 400 have poor flexibility. This concentration provided good flexibility and did not affect the film solution's viscosity.

\section{Characterization of film coated polymer}

Organoleptic and morphological evaluation

The obtained PGBYS film has a slightly yellowish color, odorless, and flexible. Meanwhile, the PGBYSP film coating has a slightly brownish color. The morphology of the PGBYS and PGBYSP coating films was observed using a scanning electron microscope (SEM). The result shows that the surface of the coating film is irregular and uneven. This may be due to an uneven surface of printing plate.
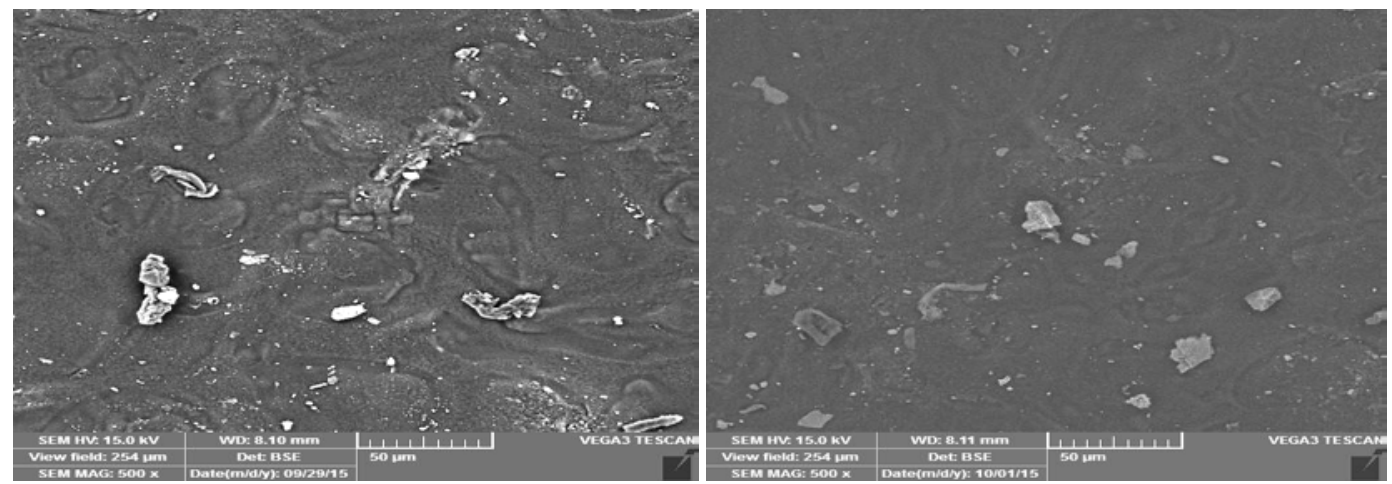

Fig. 2: SEM of the morphological shape of controlled release film coating with 500x magnificancy (a) Film using PGBYS (b) Film using PGBYSP 
Table 3: Results of the coating film characterization

\begin{tabular}{lll}
\hline Parameter & mean $\mathbf{S D}$ (n=3) & F2 \\
\cline { 2 - 3 } & $\mathbf{F 1}$ & $0.18 \pm 0.005$ \\
\hline Film thickness (mm) & $0.13 \pm 0.020$ & $0.27 \pm 0.05^{*}$ \\
Tensile strength (MPa) & $0.08 \pm 0.005^{*}$ & $164.06 \pm 57.94$ \\
\% Elongation & $114.16 \pm 11.81$ & $1.8 \times 10^{3} \pm 7.9 \times 10^{-4}$ \\
Young's modulus (MPa) & $7.3 \times 10^{4} \pm 9.8 \times 10^{-5}$ & \\
Film solubility (\%) & & \\
-HCl pH 1.2 & $7.9 \pm 1.92^{*}$ & $25.8 \pm 2.42^{*}$ \\
-Buffer phosphate pH 6.8 & $8.6 \pm 2.27$ & $11.6 \pm 1.44$ \\
-Buffer phosphate pH 7.4 & $19.1 \pm 5.46$ & $13.1 \pm 1.78$ \\
\hline
\end{tabular}

Data represents mean $\pm S D(n=3), *$ Statistically significant difference at *p<0.05

The characterizations of coatings film have been investigated and results were shown in table 3 .

\section{Film thickness}

The result shows that the film thickness of F1 and F2 does not differ much and is still within the range for coating film of 0.1-0.5 $\mathrm{mm}$ [21].

\section{Mechanical strength}

It can be seen from the mechanical strength between F1 and F2 that chemical modification does not increase the mechanical strength of the film coating. The concentration of plasticizer also affects mechanical strength. High concentration of plasticizers causes the tensile strength to decrease due to reduced intermolecular interactions [22]. This interaction is reduced due to the presence of glycerol which breaks hydrogen bonds between polysaccharide molecules [23].

\section{Film solubility}

The solubility was accomplished by incubating the film in a fluid representing acidic stomach and alkaline intestinal condition. In an acidic stomach, small intestine and colon, a medium $\mathrm{pH}$ of $1.2,6.8$, and 7.4 were used, respectively [24].

According to table 3, F1 and F2 dissolved in an alkaline medium, but F2 did not maintain its condition in an acidic medium, hence releasing the drug content before reaching the intestinal area. This proves that film coatings produced through chemical modification by esterification withstand an acidic medium. Free carboxylate groups in phthatate starch because the PGBYSP film coating to ionize more in alkaline conditions. Besides, DS also affects starch solubility at lower and higher $\mathrm{pH}$ values. The more phthalate groups are substituted, the more difficult it is for starch to ionize in an acidic medium [10].

\section{CONCLUSION}

Conclusively, the film-forming polymer of modified Banggai yam starch was soluble in an alkaline medium, while F2 failed to maintain its conditions in the acidic medium. This proves that the coating subjected to chemical modification by esterification stands acidic conditions. Therefore, PGBYSP has the potential to be used as a coating agent in a modified release dosage form.

\section{ACKNOWLEDGEMENT}

The authors thank to Ministry of Research, Technology and Higher Education, Republic of Indonesia that financially supported the study via grant of scheme of "HIBAH BERSAING".

\section{FUNDING}

Nil

\section{AUTHORS CONTRIBUTIONS}

All the authors have contributed equally.

\section{CONFLICTS OF INTERESTS}

\section{Declared none}

\section{REFERENCES}

1. Allen LV, Ansel HC. Ansel's pharmaceutical dosage forms and drug delivery systems: Tenth edition. Ansel's pharmaceutical dosage forms and drug delivery systems: Tenth Edition; 2014.
2. Zaid AN. A comprehensive review on pharmaceutical film coating: past, present, and future. Drug Design Dev Ther 2020;14:4613-23.

3. Seo KS, Bajracharya R, Lee SH, Han HK. Pharmaceutical application of tablet film coating. Pharmaceutics 2020;12:1-20.

4. Surini S, Gotalia F, Putri KSS. Formulation of mucoadhesive buccal films using pregelatinized cassava starch phthalate as a film-forming polymer. Int J Appl Pharm 2018;10:225-9.

5. Zhang Y, Rempel C, Liu Q. Thermoplastic starch processing and characteristics-a review. Crit Rev Food Sci Nutr 2014;54:1353-70.

6. Ellis WO, Oduro I, Asiedu R. Physicochemical and pasting characteristics of water yam (D. alata) in comparison with pona (D. rotundata) from ghana. Source 2011;3:149-58.

7. Alcazar Alay SC, Meireles MAA. Physicochemical properties, modifications and applications of starches from different botanical sources. Food Sci Technol 2015;35:215-36.

8. Nawaz H, Waheed R, Nawaz M, Shahwar D. Physical and chemical modifications in starch structure and reactivity. In: Chemical Properties of Starch; 2020.

9. Dimantov A, Kesselman E, Shimoni E. Surface characterization and dissolution properties of high amylose com starch-pectin coatings. Food Hydrocoll 2004;18:29-37.

10. Surini S, Putri KSS, Anwar E. Preparation and characterization of pragelatinized cassava starch phthalate as a ph-sensitive polymer for enteric coated tablet formulation. Int J Pharm Pharm Sci 2014;6:17-24.

11. Andrade LA, Barbosa NA, Pereira J. Extraction and properties of starches from the non-traditional vegetables Yam and Taro. Polimeros 2017;27:151-7.

12. Alabi CO, Singh I, Odeku OA. Evaluation of natural and pregelatinized forms of three tropical starches as excipients in tramadol tablet formulation. J Pharm Investig 2018;48:1-8.

13. Lajide L, Ayodele O, Ekiti A. Synthesis and characterization of native and pre-gelatinized cassava starches. Am J Innov Res Appl Sci 2019;9:418-24.

14. USP US. Pharmacopoeia-national formulary [USP 38 NF 33] Rockville Md United States Pharmacopeial Conv; 2015.

15. SNI Standard in Indonesia. 08-7070-2005 Determination of Moisture Content Using Heating or Oven [Internet]. 2005. Available from: www.sni.go.id [Last accessed on 05 Feb 2021]

16. Lecomte F, Siepmann J, Walther M, MacRae RJ, Bodmeier R. Blends of enteric and GIT-insoluble polymers used for film coating: physicochemical characterization and drug release patterns. J Controlled Release 2003;89:457-71.

17. Sumardiono S, Riska L, Jos B, Pudjiastuti I. Effect of esterification on cassava starch: physicochemical properties and expansion ability. Reaktor 2019;19:34-41.

18. Oko A, Famurewa A. Estimation of nutritional and starch characteristics of Dioscorea alata (Water Yam) varieties commonly cultivated in the South-Eastern Nigeria. Br J Appl Sci Technol 2015;6:145-52.

19. Imre B, Vilaplana F. Organocatalytic esterification of corn starches towards enhanced thermal stability and moisture resistance. Green Chem 2020;22:5017-31.

20. Jarray A, Gerbaud V, Hemati M. Polymer-plasticizer compatibility during coating formulation: a multi-scale investigation. Prog Org Coatings 2016;101:195-206. 
21. Mitlin VS. On dewetting conditions. Colloids Surf A 1994;89:97101.

22. Sanyang ML, Sapuan SM, Jawaid M, Ishak MR, Sahari J. Effect of plasticizer type and concentration on tensile, thermal and barrier properties of biodegradable films based on sugar palm (Arenga pinnata) starch. Polymers 2015;7:1106-24.
23. Basiak E, Lenart A, Debeaufort F. How glycerol and water contents affect the structural and functional properties of starch-based edible films. Polymers 2018;10:1-18.

24. Sonali Mehta L, Gowda DV, Vishal Gupta N, Manohar M. Formulation and development of lenalidomide loaded delayed release mini tablets in capsules. Int J Appl Pharm 2018;10:239-42. 